\title{
Reinventing community in COVID-19: a case in Canberra, Australia
}

\author{
Richard $\mathrm{Hu}^{1}$ (1) \\ Received: 17 May 2020 / Accepted: 11 June 2020 \\ (c) Springer Nature Singapore Pte Ltd. 2020
}

\begin{abstract}
In this essay, I share my experiences and reflections of fighting COVID-19 from the perspective of a resident and a planner living and working in Canberra, Australia. I focus on three themes of building community compassion and collaboration and regard them as potential opportunities deriving from this crisis. First, COVID-19 presents a compulsory situation for establishing a virtual community and practising smart work. Second, COVID-19 helps rediscover a local community and nurture a special community spirit under the social distancing circumstance. Third, COVID-19 creates more opportunities of engaging and understanding nature, interestingly, in a context of staying home. These three themes are in large part rooted in the local communities of a city that is known for low density and being a 'bush capital' and possibly suggest some rethinking about the city’s planning legacy.
\end{abstract}

Keywords COVID-19 $\cdot$ Virtual community $\cdot$ Local community $\cdot$ Natural community $\cdot$ Smart work $\cdot$ Canberra

\section{Seeking local opportunities in a global crisis}

COVID-19 has paused the world. It is an unusual situation-an unwanted one although-under which we have to adapt, reflect, and envision. In the long process of human evolution, we have inherited and developed the wisdom of surviving a crisis dialectically: a crisis is often the prelude to opportunities. COVID-19 is a global disruption; but local impacts and responses vary. Here, I share my experiences and reflections of fighting the coronavirus as a resident and a planner living and working in Canberra, Australia's capital city. I focus on building compassion and collaboration along three community-centric themes: a virtual community, a local community, and a natural community. These three themes are suggestive of some potential opportunities deriving from this crisis. They also inform some rethinking of the planning legacy of Canberra as a planned city.

A brief introduction to Canberra's economic, social, and environmental backgrounds assists with an understanding of my experiences and reflections. Within the national urban system, Canberra's 'industry' is government and education.

Richard $\mathrm{Hu}$

richard.hu@canberra.edu.au

1 Faculty of Business, Government and Law, University of Canberra, Bruce, ACT, Australia
The city's economic base and identity is being diversified from a government city to a knowledge city that produces knowledge, information, innovation, and decision $(\mathrm{Hu}$ 2015). Canberra has a population of more than 400,000 on a vast land area of $814.2 \mathrm{~km}^{2}$ mostly of natural environment. The city's built environment is characterised by low density, sprawl, and a predominant transport mode of private cars. These features of the natural and built environments win the city a nickname of 'bush capital', as typified in suburb Coombs where I live (Fig. 1). These features have influenced the way COVID-19 has been tackled in the local communities of the city.

Canberra recorded its first COVID-19 case on 12 March 2020. As of 8 June 2020, a total of 108 cases and three deaths were reported. The latest new case-a traveller from overseas-was recorded on 7 June. This was the first new case in 34 days. In Australia as a whole, 7265 cases and 102 deaths have been reported. The crisis' hit on Canberra is less severe than many places elsewhere in the nation and the world. But the social and economic impacts are no less, regardless of the lower numbers of cases and deaths. Restrictions on activities started to be eased by phases from midMay. Below I delve into the three themes on community compassion and collaboration, drawing upon my experiences and reflections under this COVID-19 crisis. 


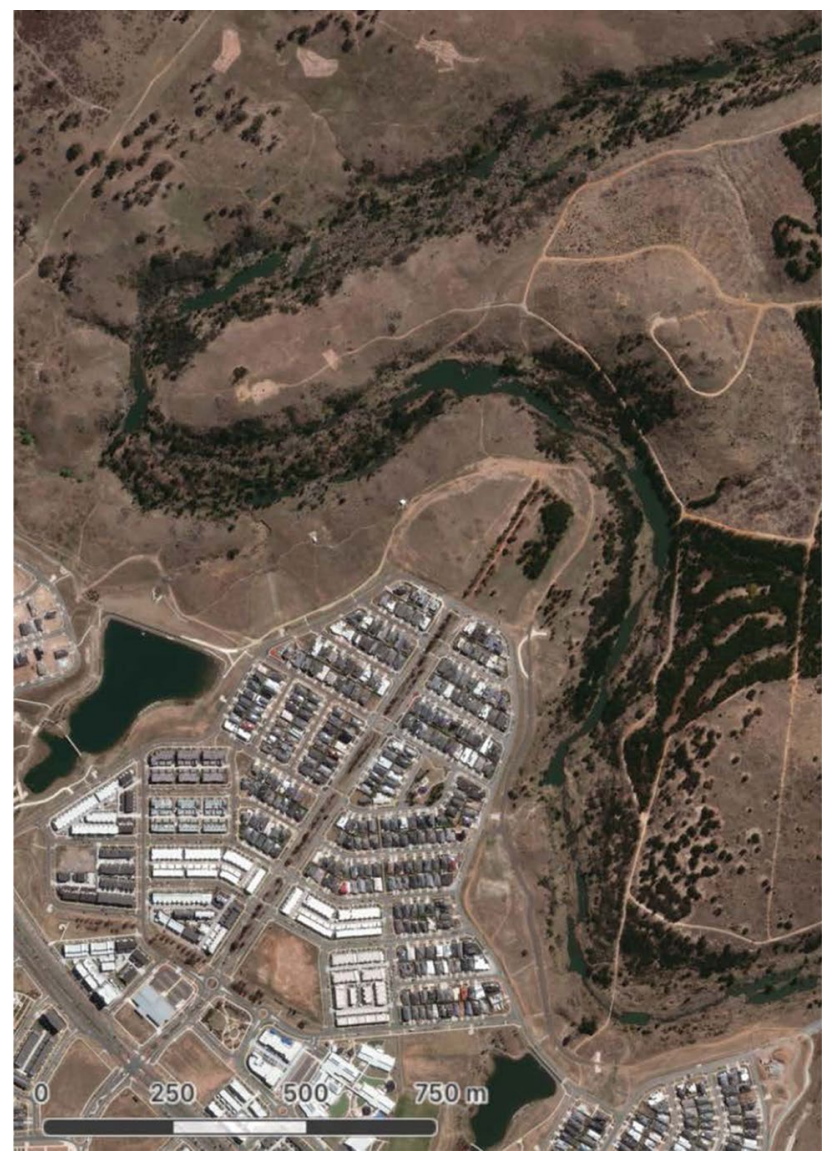

Fig. 1 Bush capital community Source: Apple maps

\section{Establishing a virtual community}

Working from home is not new for me as an academic; it is not new, either, for people whose work is about creating and transmitting knowledge and information. However, COVID-19 created a context in which we had no alternative mode of work. I was able to practise, observe, and test some propositions of smart work that I have researched and advocated for in recent years. Smart work is essentially about a new way of working, characterised by temporal-spatial flexibility and facilitated by the knowledge economy and information technological advancement $(\mathrm{Hu}$ 2019). It challenges many norms of work, management, planning, and spatial design, which were established in an industrial age. We cannot fathom the long-term influence of smart work at this stage yet-it is an emerging trend and is gaining momentum.

Although smart work is more than just working from home, COVID-19 made at least one mode of smart work an imperative and a compulsion to test its possibility and feasibility. Certain barriers of smart work are not technological, but cultural: resistance may come from both managers and employees for different concerns (Hu 2019). COVID-19 removed 'all' resistance to smart work and enforced a practice-a social experiment that could exist in theory only. It is too early to conclude that smart work has survived the crisis, but COVID-19 boosted an acceptance of it and spurred an interest in exploring its postCOVID opportunities. This smart work boom will naturally join the sustainability discourse of climate change, commuting, and urban sprawl-all confronting Australian cities and communities-to seek possible contributions of smart work to these challenges.

Technically, transition to smart work was a reasonably smooth process in my case. Closure of campus of the University of Canberra, where I work, and the arrangement of working from home occurred in the middle of the semester. This meant that we had to shift face-to-face teaching to online platform without much leeway of preparation. The difficulty, in a technological sense, was not as huge as worried or imagined. I obtained some technological literacy, which I had planned to do for some time but did not have a chance or push to action. The whole shift to online teaching was completed within one week. Compared to technological readiness, pedagogical adaptation is a subject of less tangibility and certainty: I am still in process of comprehending and evaluating the online teaching and learning experiences for students. Business communications and meetings with colleagues and collaborators also went online promptly. Despite being an advocate for smart work, I used such digital tools as Blackboard Collaborative, Zoom, Microsoft Team, and Voov for the first time and quickly became a fond user of them.

A virtual community was instantly established with my students and colleagues to replace the campus community. I have observed a distinct sense of the compassion, collaboration, collegiality, and solidarity that is special to this virtual community, in part because we have a shared understanding of the common challenges, in part because the new digital environment creates a demand for closer inter-personal relationality that may not be necessary when we meet in person.

Further, this virtual community significantly expanded the border of my connectivity or simply made it borderless. Here are several examples to illustrate this expanded or borderless connectivity. First, I participated in a webinar on COVID-19 that included a dozen of speakers across the globe and attracted more than 50 participants. Normally, such an activity would mean an international conference requiring an international return flight, accommodation, registration fee, and several days of travel. I do not recall many international conference sessions that attracted more than 50 participants before. Second, I participated in a triparty business meeting with colleagues in New Zealand and China, which was 'naturally' organised online these days. Third, I was invited to give an online talk for students at the 
Guizhou Minzu University, China, as part of their seminar series under this virtual educational situation. Five years ago, I gave a talk for them: it was an international trip of four days.

None of these concepts and practices of establishing a virtual community are new. COVID-19 exposed them to an extent unwitnessed before. Technology is advancing exponentially; cultural path dependence and attitudinal resistance to change are being disrupted. The process of reconfiguring a virtual community seems to be speeding up and is likely to become a new normal in the way we work and live. In Australian cities, a 'COVID-change' phenomenon is reported, showing that young people are looking to live in regional centres to pursue a more relaxed lifestyle after the experiment with working from home, which has proven viable and productive (Redman 2020). The post-COVID era may not be an end of this phenomenon, but a start.

\section{Rediscovering a local community}

Social distancing impacted the sense of community. However, it also triggered a new community spirit—one that was nurtured in the unusual social distancing context only and thus helped rediscover a local community. The government classified outdoor exercise as an essential activity, as essential as shopping for food and accessing medical services, under stay-home restrictions. I immediately observed a surge of people walking and jogging around the neighbourhood, individually or with family members and pets, although local playgrounds were closed. I witnessed a livelier neighbourhood than usual, paradoxically, under a social distancing circumstance, in a low-density precinct mostly of detached houses (Fig. 1). The rule of social distancing was generally respected. However, it was clear that people were more willing to politely engage with community members through eye contacts, smiling, and nodding heads in silence, or through a very brief conversation in distance, to express understanding, support, and encouragement. An untold feel that we are one community permeated.

The most touching experience of this community spirit was probably the 'bear hunt' initiative that became popular in Australia and internationally. I do not know how, when, and where it started. Said to be inspired by the classic children's book We're Going on a Bear Hunt, residents placed Teddy bears, or any animal toys, in the front windows to engage and amuse kids when they walk around the community with parents and families. Bear hunts provided me with invaluable time to play with my five-year-old boy and to engage and understand our local community. We created maps, drew routes of hunting, recorded the bears, and shared the experiences and outcomes with his teacher and classmates at online class. We explored many places of our neighbourhood where we had never been before. Those toy bears symbolise a spirit to survive the crisis and signify a hope for the future (Fig. 2). Underlying this symbolism is a manifest compassion, understood as a universal human feeling and support for those who are the weak and are suffering (Goetz et al. 2010; Strauss et al. 2016). This compassionuntold but felt-lingers on.

Crisis challenges and disrupts a community in some way. Crisis also solidifies a community and engenders a community spirit. COVID-19 enabled me to rediscover a local community, to which I and my family have a stronger sense of belonging than before. Our experience is not exceptional. A survey study reveals an increase of social trust and cohesion despite heightened anxiety, distress, uncertainty, and socio-economic challenges across Australia during COVID19 (Biddle et al. 2020). Crisis unites people; crisis creates compassion and collaboration.

\section{Engaging a natural community}

Staying home and activity restrictions seemed to usher in unprecedented opportunities to engage nature. The community where I live is next to a bush land of hills and a river (Fig. 1). I do not recall that I ever had more frequent bush walks with my family than the COVID-19 period. We had a strong drive to go to the bush for a walk almost on a daily base: all family members were at home; a bush walk was a legitimate activity; nothing seemed more important than outdoor exercises in this health crisis. In this family physical

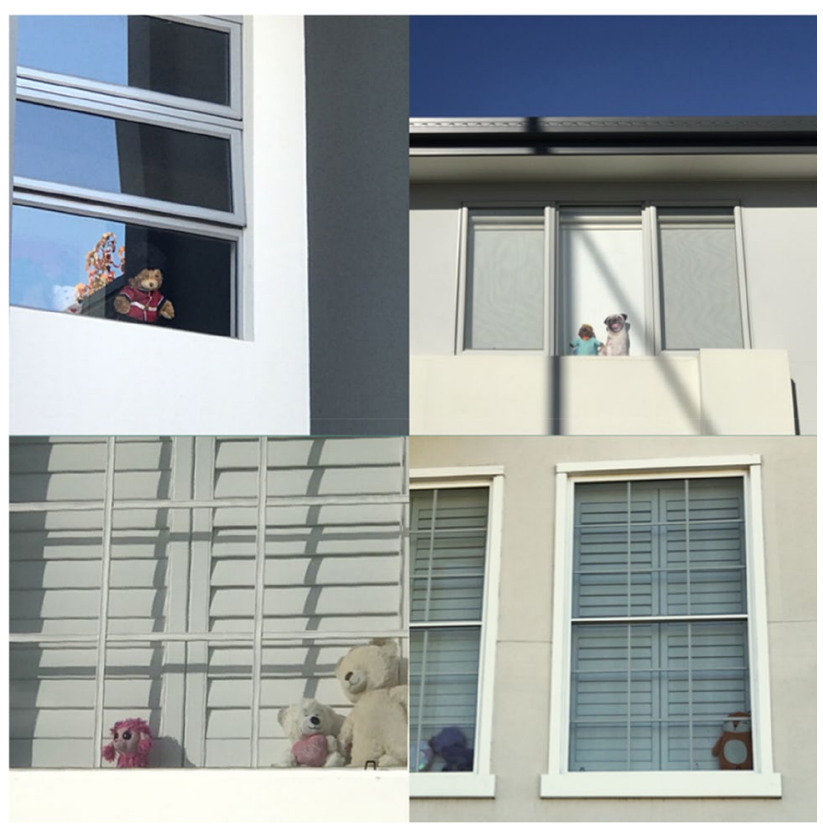

Fig. 2 Bear hunts Source: The author's photography 


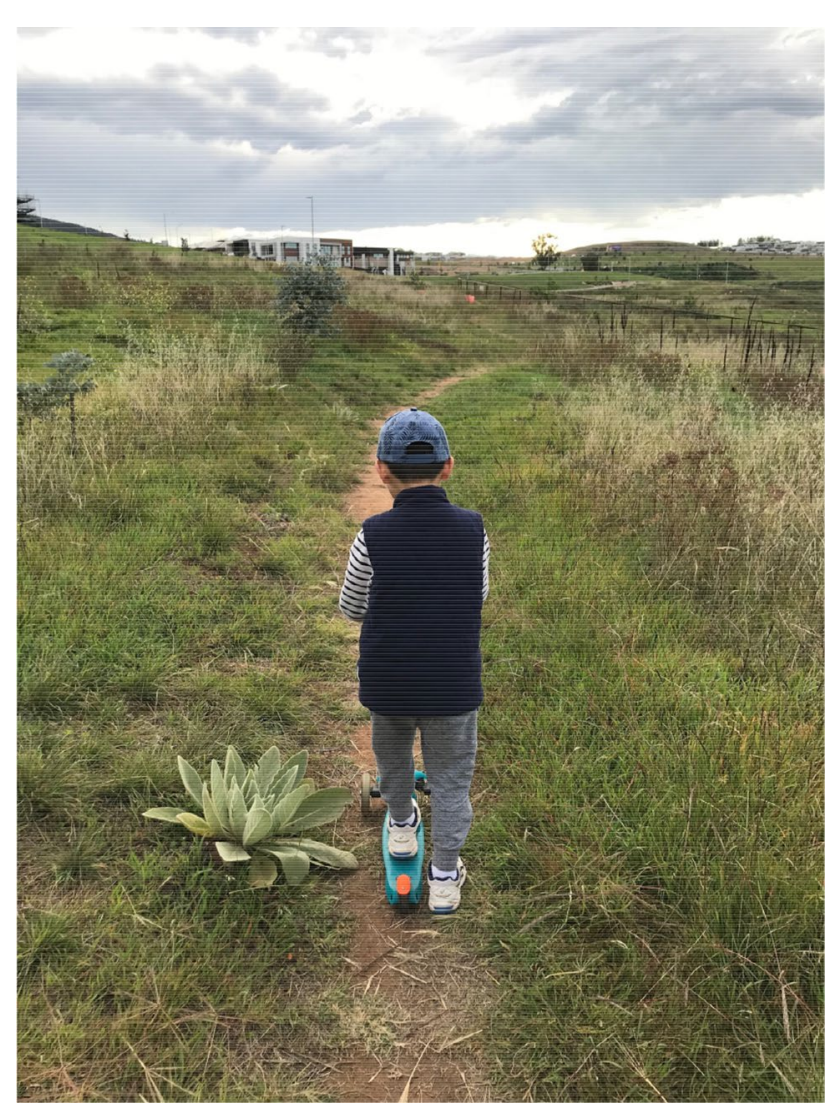

Fig. 3 Engaging nature Source: The author's photography

exercise, my boy could experiment with riding a scooter in a bush trail (Fig. 3). Bush walk was also an educational opportunity: the kid could explore and learn about nature when the school was closed; the adults could reflect on the relationship between human and nature. If it were not for COVID19 , I could not have engaged nature within the vicinity of our community to such an extent. I was intrigued by an educational board on a diverse ecosystem in the local reserve (Fig. 4). I had a digestion of its information on local plant and ecosystem and had some pondering about the implications of this crisis for human-nature relationship. Indeed, a major lesson of COVID-19 is that we need to rethink the coexistence between human beings and other beings and to mindfully pursue both human health and ecosystem health (Chen and Yuan 2020; Wang 2020).

We are not the only family that chose to engage nature. I never witnessed more people, mostly in families, walking or riding along the trails in the bush. It presented an unusual image that would be hardly believable otherwise: a normally quiet bush area suddenly became lively with humans and human activities, ironically, under activity restrictions. There were occasions when we even had 'traffic jams' on the narrow bush trails, and we had to wait to give way to each other. People gestured and greeted, all knowing why we

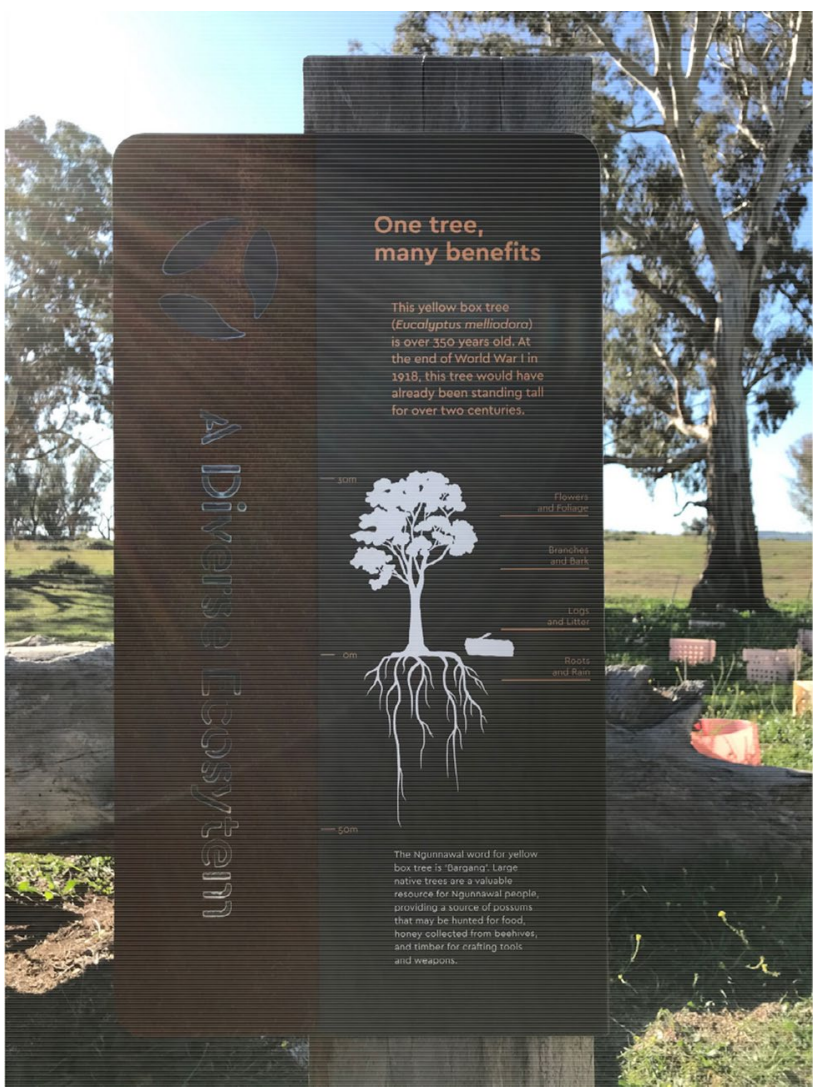

Fig. 4 Learning from nature Source: The author's photography

ended up being here, staying away from our community and creating a natural community. The Canberra Times reported that the city's urban reserves and nature parks had experienced record use, and the walking trails have never been busier (Bladen 2020). A community that we would expect in a built environment seemed to be transplanted to a natural environment, in a response to COVID-19.

\section{Concluding remarks}

The world is still in the middle of fighting COVID-19. The severity of the crisis varies by places; the approaches to fighting it differ. The three themes of community compassion and collaboration that I have identified are locally rooted. They are built upon several key characteristics of the local communities in Canberra: a diverse and multicultural society, low-density built environment, easy access to natural environment, a knowledge economy, and a highly educated workforce. These characteristics have impacted the way COVID-19 has been tackled in the local context, and the way the community is being reinvented in the crisis.

The COVID-19 experiences may call for a rethinking of the city's planning legacy. Canberra is a planned city: the 
twentieth century's modernist planning tradition created a 'garden city' and a 'bush capital', which is appreciated and celebrated; on the other hand, the resultant urban form of low density and urban sprawl has been the target for containing in the twenty-first century's planning ethos for compactness and densification (Hu 2020). The city's built environment and green space, which are sometimes criticised for being a modernist planning legacy, proved to be a valuable asset in fighting COVID-19. COVID-19 is also generating a global debate on built environment and public health-the very problem attributed to the genesis of modern planning.

Despite the diversity of local social, cultural, economic, political, and environmental settings around the globe, we are one in confronting the challenge towards a shared future, through scientific discovery and invention, through effective governance and policy making, and through building community resilience and capacity. In Australia and many places around the world, we are easing restrictions, and are gradually shifting to the normal, involving restoring an old normal and creating a new normal. In many senses, COVID-19 is a dividing line. Globally, it is a dividing line of globalisation, global economic system, and international relationship. Locally, it is a dividing line of rebuilding and reinventing our communities. Crises come and go; opportunities may stay on; reflections must stay on.

\section{References}

Biddle N, Edwards B, Gray M, Sollis K (2020) Hardship, distress, and resilience: the initial impacts of COVID-19 in Australia. ANU Centre for Social Research and Methods, Canberra

Bladen L (2020) 'Record use' of Canberra's parks and reserves but people warned after dogs cause damage. The Canberra Times. https ://www.canberratimes.com.au/story/6736105/record-use-of-canbe rras-parks-and-reserves-but-not-everyone-is-following-the-rules $/$ ?cs $=14329$. Accessed 3 May 2020
Chen L, Yuan X (2020) China's ongoing battle against the coronavirus: why did the lockdown strategy work well? Soc Ecol Pract Res. https://doi.org/10.1007/s42532-020-00048-1

Goetz JL, Keltner D, Simon-Thomas E (2010) Compassion: an evolutionary analysis and empirical review. Psycholog Bull 136:351-374

Hu R (2015) Canberra's competitiveness in the national context. Policy Stud 36:55-71

Hu R (2019) Spatial disruption and planning implication of the sharing economy: a study of smart work in Canberra, Australia. Int J Knowl Based Dev 10:315-337

$\mathrm{Hu}$ R (2020) Remaking the border: the proposed border expansion of Canberra in the 1960-1970s revisited in the planning and development context of the 21 st century. Plan Perspect. https://doi. org/10.1080/02665433.2020.1747027

Redman E (2020) COVID-change: it's the new tree-change or seachange for city dwellers. https://www.domain.com.au/news/covid -change-its-the-new-tree-change-or-sea-change-for-city-dwellers954376/. Accessed 12 May 2020

Strauss C, Taylor BL, Gua J, Kuyken W, Baer R, Jones F, Cavanagh K (2016) What is compassion and how can we measure it? A review of definition and measures. Clin Psychol Rev 47:15-27

Wang Y (2020) China's ongoing battle against the coronavirus: a scholar-practitioner's experiences and reflections. Soc Ecol Pract Res. https://doi.org/10.1007/s42532-020-00047-2

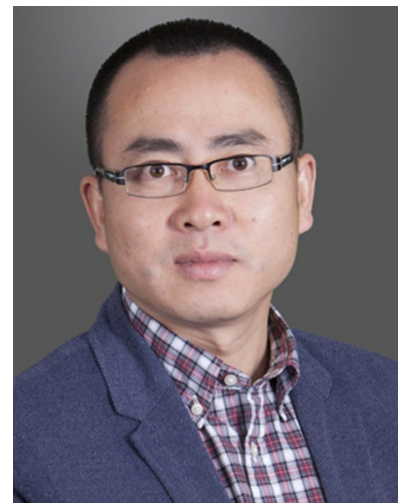

Richard Hu is an award-winning urban planner. His scholarly and professional interests integrate urban design, urban science, and urban policy to investigate and address contemporary urban transformations and challenges, with a focus on the Asia Pacific area. His latest book is The Shenzhen Phenomenon. 